\title{
ESTADISTICA
}

\section{A donde no llega la experiencia personal, llega el instrumento estadístico}

\author{
Entidades territoriales (Municipios) \\ y entidades funcionales (Sindicatos) \\ han de armonizar su acción con un \\ común espíritu de servicio
}

Dada la importancia, cada vez mayor, que dentro del conjunto de las estadisticas nacionales van adquiriendo las de carácter local o sea la Estadistica municipal, importancia considerada y prevista en la vigente Ley de Estadistica y en su Reglamento de aplicación que disponen la obligada colaboración de la Administración Local para ia formación de las estadísticas de población, facultando a la vez a dicho organismo para la confección de las estadisticas necesarias al cumplimiento de sits propios fines, hemos considerado de gran interés traer a estas páginas opinión autorizada en la materia como la del Ilustrísimo señor don Carlos Ruiz del Castillo, prestigioso catearático de la Universidad Central y actual directior del Instituto de Estudios de Administración Lo'cal, órgano superior de estudios y asesoramiento de los cada día más complejos problemas municipales.

Abusando de su amable y cordial acogida y amparado en su amena e interesantísima conversación, he ampliado la serie de preguntas que llevaba previstas, sin que por ello haya decaído la amabilidad del señor Ruiz del Castillo, a quien pido perdón por est'e pequeño abuso, que espero encuentre justificado.

He aqui las interesantes contestaciones del director del Instituto de Estudios de Administración Local a las numerosas preguntas formuladas:

- ¿Qué importancia atribuye usted a la Estadistica en la actual organización administrativa municipal?

- La Estadística es el instrumento de captación de la vida moderna con su creciente complejidad. Cabe decir que es el ojo que mira los fenómenos colectivos. De aquí que cualquier intento de reforma, 
del orden que sea, haya de estar precedido por la acumulación de un copioso material estadístico debidamente relacionado.

Aparte de esta consideración general, para los Municipios ofrece la Estadística una doble vertiente. Por una parte, los Ayuntamientos son los órganos más próximos a las fuentes de la vida colectiva, y todos los hechos y actividades demográficas, sociales y económicas quedan primariamente reflejados en los registros y ficheros municipales. Pero, además, constituyen los órganos de que indispen. sablemente ha de servirse ei Estado para extender su acción a todo el territorio nacional, y, así, en el aspecto que enjuiciamos, son auxiliares primarios de la accićn estadística del Estado. Piénsese en cl doble carácter que el Municipio ofrece -como expresión de una vida local propia y como división del territorio nacional-y parecerá clara también esta doble finalidad de su acción estadística.

- ¿Qué misión informativa y estadística cree. usted, por consiguiente, que compete a los Municipios?

- Se deduce de lo anterior. Los Ayuntamientos suministran hoy una cantidad considerable de datos estadísticos a los diversos Departamentos ministeriales y a los organismos autónomos.

Concretamente, el Instituto de Estudios de Administración Local no puede elaborar sus estadísticas sino con la cooperación, por cierto esmeradísima, de las Oficinas municipales. La visión completa del panorama español, pues España es el conjunto de sus entidades locales, se está obteniendo mediante una canalización de la corriente de datos estadísticos que procede de los 9.250 Municipios que, en números redondos, existeri en España.

Se comprenderá que el trabajo estadístico que pesa sobre los Ayuntamientos es de gran volumen. En los Municipios de tipo medio o rural, esta labor atarea extraordinariamente al Secretario, o cuando existe, al funcionario encargado; en las grandes ciudades, los funcionarios dedicados normalmente a trabajos de Estadística suman el centenar. Así, en Madrid y en Barcelona.

- ¿Cómo cree usted posible organizar la abrumadora tarea estadistica que en la actualidad pesa sobre los Ayuntamientos?

- Hasta hace poco tiempo, los trabajos de estadísticas se orga. nizaban por cada Ayuntamiento con la genial improvisación que caracteriza tantas cosas en España. Las exigencias del momento iban señalando pautas a la voluntad de servicio. Pero se ha sentido la necesidad de establecer una coordinación que, respetando la autonomía de cada Corporación, permita realizar estos trabajos con sujeción a plan común, a fin de que los datos puedan ser contrastados en un balance comparativo y las estadisticas respondan así a las normas (standars) de la moderna técnica estadística.

- ¿Considera necesaria la organización de oficinas de estadistica municipal?

- La respuesta afirmativa a esta pregunta va implícita en lo dicho anteriormente. Hoy, los Ayuntamientos más importantes de España, como los del extranjero, tienen establecida una Sección u 
Oficina de Estadística. Otros que no tienen organizado el servicio con suma de elementos, dedican un funcionario a esta labor.

En los Municipios menos importantes, dificultades conocidas de presupuesto impiden la especialización, $\mathrm{y}$ las exigencias estadísticas tienen que ser distribuídas entre otros servicios a cargo de funcionarios municipales.

Es corriente, por cierto, el afán con que los modestos funcionarios de los pequeños Municipios responden a nuestras encuestas y se afanan en cumplir los servicios que se les encomiendan.

En defecto de Oficinas estadísticas en todos los Ayuntamientos. la precisión de los cuestionarios que les envía el Instituto de Estudios de Administración Local, las instrucciones de que éstos van acompañadas y la comunicación incesante con todas las Corporaciones, va permitiendo establecer diręctrices que preparan seguramente un porvenir en que la unidad de criterio estará servida por una especialización funcional.

$-_{i} Y$ dentro de tal necesidad, juzga oportuna la centralización o la descentralización de esta red de Oficinas municipales?

-Del doble carácter, ya aludido, del Ayuntamiento, se deduce que la cooperación al servicio estadístico de los diversos Ministerios, de la Dirección general del ramo y del Instituto de Estudios de Administración Local ha de responder a un criterio unitario y ha de recibir un impulso único. Cuando se trata de satisfacer necesidades del propio Municipio, el criterio ha de ser descentralizador, como corresponde a la peculiaridad de los propios problemas.

-Otro aspecto, también fundamental, es el de la especialización de los funcionarios municipales; ¿qué forma de conseguirla y de estimular tal especialización considera usted que debería adoptarse?

-Es siempre un problema espinoso el que se relaciona con la creación de Cuerpos. Es posible que la vida pública en todos los países se resienta ya del mal burocrático. Hay que afrontar, sin embargo, los problemas planteados por la función, sin caer en el funcionalismo.

La especialización, tratándose de servicios técnicos, es, por otra parte, indispensable, y cabe conciliar el derecho reconocido a los Municipios para designar sus funcionarios dentro de un minimum de condiciones, con el reclutamiento de éstos en sectores preparados.

Los propios cursos de perfeccionamiento que organiza el Insti. tuto de Estudios de Administración Local contienen la buena orientación en este punto.

- ¿Cuál es, a su juicio, la misión de la Estadística en el estudio de los problemas generales de la Administración Local?

-A donde no llega la experiencia personal, insustituíble, pero de campo de aplicación reducido, ni la doctrina pura, que cuando no está contrastada en los hechos es abstracción estérịl, llega el instrut mento estadístico, básico en el conocimiento de un gran número de hechos, y el cual permite obtener resultados que sirven juntamente para preparar las reformas y para aclimatarlas. 
Áñádase a todo ello las posibilidades que ofrecen las estadísticas municipales para contrastar resultados y para cotejar la situación de los Municipios nacionales con los extranjeros.

- La vigente Ley de Estadística y su Reglamento de aplicación, destacan, muy fundamentalmente, la misión de la Estadística munici. pal, ¿no es asi?

-Efectivamente, el Reglamento de 2 de febrero de 1948 se preocupa de la utilización, determinada en la Ley, de las Estadísticas municipales que tienen carácter nacional. A la coordinación de tra. bajos corresponde la de Organismos, y entre dos extremos viciosos -el que absorbe y el que desintegra-, el Instituto de Estadística ha elegido el buen camino: el que conduce a coordinar y a articular.

- $Y$ pasando ya a aspectos concretos de esta importante misión informativa y asesora, ¿̇cómo está organizada la Sección de Estadística en el Instituto de Estudios de Administración Local?

- La Sección de Estadística constituye un servicio primordial del Instituto. Este, según su Ley fundamental, consta de tres Secciones: la de Documentación y Publicaciones, la formada por la Escuela Nacional de Administración y Estudios Urbanos, y la de Estadística.

Sobre las pautas trazadas por el malogrado estadístico e ilustre profesor, don Olegario Fernández Baños, que fué su primer Jefe, la Sección está hoy dirigida por un prestigioso Jefe del Cuerpo $\mathrm{Fa}$ cultativo de Estadística, don Domingo Lucas Calvo, cuyos servicios han merecido reciente recompensa oficial.

$\mathrm{El}$ resto del personal ha sido seleccionado, en gran parte, entre estadísticos profesionales, muchos de ellos pertenecientes al Instituto Nacional de Estadística.

En siete años de funcionamiento, la Sección ha recogido sus estudios en siete grandes volúmenes, amparados por el título común de "Estudios y Estadísticas de la Vida Local en España», los cuales constituyen una enciclopedia de estadísticas locales, abundantemente utilizadas en Centros oficiales, y con cuyos datos han podido ser acometidos estudios serios. Citaremos entre éstos el que recientemente ha publicado el propio Instituto sobre la «Hacienda en el Municipio rural españoln, debido al Catedrático señor Paredes Marcos, y que ha sido galardonado con el Premio "Calvo Sotelo 1947".

La publicación de los volúmenes de Estadística viene a continuar los "Anales» que sobre la vida provincial y la vida municipal inició Calvo Sotelo, inolvidable autor de ambos Estatutos. Aquellos "Anales) representaron, en el marco de su tiempo, un instrumento muy interesante. Contienen Memorias corporativas, orientadoras o reveladoras de la situación de cada núcleo local. Pero el instrumento quedó pronto truncado. Sólo fueron publicados dos volúmenes. La falta de continuidad del criterio político interrumpió una publicación que se ofrecía prometedora. Ahora, el Instituto prosigue el camino con normas acomodadas a las exigencias, mucho mayores, del tiempo, y así tras de la publicación de las Memorias que fueron pedidas 
en 1943 a las Diputaciones provinciales y a los Municipios de más de ${ }_{15} .000$ habitantes, comenzó la elaboración de estadísticas censales que han permitido aplicar normas relativas a la distribución demográfica, a los servicios principales, a los funcionarios (cuyo número, por cierto, dada la singularidad de cada Ayuntamiento, ni siquiera tenía reflejo estadístico general. En una palabra, no era conocido).

En estos momentos se encuentran en vías de elaboración datos importantísimos, para obtener los cuales se han cursado fichas muy estudiadas a los Municipios de presupuesto superior a 200.000 pese.tas. Mediante ello se aspira a conocer la situación real de las Haciendas, deduciéndola, no del presupuesto que se formula, sino del que se liquida.

También ha sido cursado un cuestionario para la observación estadística del grado de urbanización de los Municipios españoles mayores de 20.000 habitantes, y otro sobre la información relativa a beneficencia municipal, parques y jardines, continuando el estudio, ya publicado, de otras actividades municipales (aguas, mataderos, ferias y mercados, etc.).

Interesa el censo, pero importa mucho su adecuada utilización en forma asequible a los no iniciados, y sin menoscabo del rigor científico. En tal sentido hay que destacar el programa del Seminario de Estadística, recientemente constituído. Baste, por el momento, la alusión, a fin de no alargar estas contestaciones; pero los he. chos mostrarán la fecundidad del programa. Corresponde a don Javier Ruiz Almansa una parte destacada en esta organización ciertamente avalada por el prestigio de sus obras, varias de ellas publicadas ya por el propio Instituto, y otras en preparación, aparte de la preciada orientación que representa la Sección que dirige en la «Revista de Estudios de la Vida Localm.

${ }_{-i}$ Cuáles son las actuales relaciones de la Estadística municipal con el Instituto Nacional de Estadistica?

- Se ha aludido ya a ellas en anteriores respuestas. El Instituto de Estudios de Administración Local está representado por su Director en el Consejo Superior Estadístico, al que pertenece el Director general de Administración local. Ambos Centros (la Dirección general y el Instituto de Estudios de Administración local) están también representados en la Comisión Interministerial de Coordinación y Asesoramiento para las Estadísticas de Edificación y Vivienda, y en la Comisión de Padronęs.

-Y hablando de relaciones, considero de extraordinario interés para nuestra Organización, como usted comprenderá, conocer su opinión sobre las relaciones entre la Estadística municipal y la Estadistica sindical.

- No es necesario consignar que son y han de ser en todo momento de "buena vecindad», pero de vecindad compenetrada en la defensa del edificio común. España es en su proyección territorial un conjunto de Municipios, y en su proyección económica y profesional un conjunto de Sindicatos. Entidades territoriales y Entida- 
des funcionales han de armonizar su acción con un común espíritu de servicio. El Instituto de Estudios de Administración Local, por deber y por convicción, no se apartará de esta senda, y aspira a una colaboración cada vez más estrecha.

-Aunque no soy, ni mucho menos, el más indicado para ello, me permito decirle que tal sentir coincide exactamente con el del Servicio Sindical de Estadistica respecto a la Estadística municipal, ya que consideramos a anibas organizaciones estadisticas pilares básicos en que ha de apojarse la labor directriz y coordinadora que compete al Instituto Nacional de Estadistica. Por último, ¿ querria usted indicarme cuáles son en la actualidad los principales Ayuntamientos que destacan por st labor estadistica?

- No querría incurrir en omisiones. En general, hay que destacar el auxilio que prestan casi todos. Baste el dato de que para el último volumen que ha publicado el Instituto y que comprende los datos de servicios determinados en los Municipios de población superior a 1.000 habitantes, sólo cinco de los 4.200 consultados han dejado de contestar, lo cual significa que han enviado datos precisos el 99,89 por 100 de las Corporaciones consultadas.

Pero hay que referirse especialmente a los Ayuntamientos que publican Anuarios o Boletines de Estadística municipal. Citaremos a Burgos, que ha sido objeto de una distinción especial. El «Boletín de Estadística municipal de Madrid» es acreedor a los mayores elogios, como asimismo los que publican Barcelona, Bilbao y Palma de Mallorca.

Otros Ayuntamientos han hecho y siguen haciendo publicaciones monográficas de carácter ocasional y con abundante documen. tación estadistica.

\author{
R. Romero Montero \\ Director de la aRevista Sindical \\ de Estadisticas (I)
}

(1) Dado el interés de las declaraciones del Director de nuestro Instituto, recogidas por el Sr. Romero Montero y publicadas en el número de septiembre de la Revista que dirige, hemos creido oportuno reproducirlas aqui para conocimiento de nuestros lectores. 